\title{
Características de pais de origem alemã na criação de seus filhos: análise de teorias cognitivas e culturais*
}

\author{
Characteristics of parents of German origin in raising their \\ children: analysis of cognitive and cultural theories
}

Características de los padres de origen alemán en la crianza de sus hijos: análisis de las teorías cognitivas y culturales

\author{
Eloisa Capeletto**, Denise Vieira Taborda***, Lucas Demarchi \\ Gomes $^{* * * *}$, Henrique Sartori ${ }^{* * * * *}$, Maikon de Sousa Michels ${ }^{* * * * *}$
}

\begin{abstract}
RESUMO
Este artigo teve como objetivo conhecer aspectos diversos da criação dos filhos quando os pais possuem origem alemã, a partir de um diálogo entre as teorias cognitivo-comportamentais - TCC e teorias culturais. Destinou-se atenção especial às necessidades emocionais fundamentais discutidas pela terapia do esquema, uma vertente da TCC. Para tanto, foi utilizada uma pesquisa de cunho qualitativa, que se deu mediante entrevistas semiestruturadas com seis indivíduos que possuíam filhos e eram de descendência alemã: cinco mulheres e um homem. A partir da análise de conteúdo dos dados obtidos, constatou-se que o estabelecimento de um vínculo seguro, a imposição de limites e autocon-
\end{abstract} Palavras-chave: terapias cognitivocomportamentais; cultura alemã; necessidades emocionais básicas; relações pais-filhos.

\footnotetext{
* Os autores reconhecem e agradecem o apoio de todas as pessoas que se disponibilizaram a participar das entrevistas de forma voluntária. Ressalta-se que essa pesquisa foi financiada pelos próprios pesquisadores

** Discente do Curso de Psicologia da Universidade da Região de Joinville (Univille). ORCID: https://orcid.org/0000-0002-9573-2196. Contacto: eloisacapeletto@gmail.com *** Discente do Curso de Psicologia da Universidade da Região de Joinville (Univille) ORCID: https://orcid.org/0000-0001-7355-9233. Contacto: dvt.denise@gmail.com **** Discente do Curso de Psicologia da Universidade da Região de Joinville (Univille) ***** Discente do Curso de Psicologia da Universidade da Região de Joinville (Univille)

Mestre em Patrimônio Cultural e Sociedade. Especialista em Neuropsicologia e em Psicoterapias Cognitivas pelo Instituto Paranaense de Terapia Cognitiva (IPTC). Docente do Curso de Psicologia da Universidade da Região de Joinville (Univille). ORCID: https://orcid.org/0000-0002-1242-0593
} 
trole, assim como o incentivo a autonomia e independência são as necessidades mais valorizadas pelos pais. Ficou evidente também que as influências recebidas dos pais repercutem na criação de seus filhos e que o conhecimento teórico auxilia a distinguir pontos positivos e negativos dessa criação.

\begin{abstract}
This article aimed to meet many aspects of child-rearing when parents are German descendants, from a dialogue between cognitive-behavioral theories- CBT and cultural theories. Focused on special attention to fundamental emotional needs by schema therapy, a part of CBT. For that, a qualitative research was used, which took place through semi-structured interviews with six individuals who had children and were of German descent: five women and one man. From the content analysis of the data obtained, it was noted that the establishment of a secure link, the imposition of limits and self-control, as long as encouraging autonomy and independence are the requirements most valued by parents. It was also evident that the influences received from parents resonate in child-rearing and so the theoretical knowledge helps to distinguish positive and negative points of this upbringing.
\end{abstract}

\section{RESUMEN}

El objetivo de este artículo fue explorar diferentes aspectos de la crianza de los hijos cuando los padres son de origen alemán, basándose en un diálogo entre las teorías cognitivo-conductuales - TCC y las teorías culturales. Se prestó especial atención a las necesidades emocionales fundamentales tratadas por la terapia de esquemas, una rama de la TCC. Para ello, se utilizó una investigación cualitativa, que se llevó a cabo a través de entrevistas semiestructuradas con seis personas que tenían hijos y eran de ascendencia alemana: cinco mujeres y un hombre. A partir del análisis de contenido de los datos obtenidos, se encontró que el establecimiento de un vínculo seguro, la imposición de límites y el autocontrol, así como el fomento de la autonomía y la independencia son las necesidades más valoradas por los padres. También se puso de manifiesto que las influencias recibidas de los padres repercuten en la crianza de los hijos y que los conocimientos teóricos ayudan a distinguir los puntos positivos y negativos de esta crianza.
Keywords: cognitivebehavioral therapy; German culture; basic emotional needs; parentschildren relations.

Palabras clave: terapias cognitivoconductuales; cultura alemana; necesidades emocionales básicas; relaciones padres-hijos. 


\section{Introdução}

A relação entre o social e o indivíduo influencia na maneira como ele avalia diferentes eventos ou estímulos e determinam o tipo, a intensidade e a persistência das emoções e reações diversas vinculadas a eles (Gonçalves, 2014). Esse processo se dá diante do convívio em escolas, igrejas, associações e, em especial, nas dinâmicas familiares (Groth \& Hoch, 2011).

Nesse quesito, Lordelo, Fonseca e Araújo (2000) destacam que as crenças parentais possuem efeitos pertinentes nas práticas de cuidado e essas práticas, por sua vez, influenciam o desenvolvimento infantil, uma vez que são os pais que costumam mediar os princípios que são seguidos pelo grande grupo. Entretanto, ressalta-se que as direções dessas influências, bem como as interligações entre elas, não são evidentes. A partir disso, forma-se a complexa natureza das relações entre cultura, crenças parentais, práticas de cuidado e comportamento da criança.

Pontua-se que práticas pouco construtivas e a privação de envolvimento afetivo com pais e mães constituem fatores de risco para o desenvolvimento cognitivo e social e desempenho acadêmico da criança, aumentando sua vulnerabilidade a eventos ameaçadores externos ao seu ambiente familiar (Cia, Pereira, Del Prette \& Del Prette, 2006). Macarini, Martins, Sachetti e Vieira (2010) inclui que a maneira como os pais agem e pensam formam um conjunto organizado de ideias que estão implícitos na atividade cotidiana, julgamentos, escolhas e decisões dos filhos e que, compreendendo a teoria cognitiva, modulam as crenças adaptativas ou desadaptativas desses sujeitos.

Darling e Steinberg (1993 apud Brás et al., 2008) também trazem três aspectos principais relacionados às ações parentais que influenciam no desenvolvimento dos filhos, seriam eles: os objetivos primordiais relacionados à socialização; as práticas parentais utilizadas para ajudar a criança ou adolescente a atingir esses objetivos; e o clima emocional no qual ocorre a socialização.

Macarini et al. (2010), compreendendo essa relação, traz três modelos culturais de self que possuem impactos nos processos de desenvolvimento global da criança. O primeiro modelo é nomeado independente, o qual prioriza metas pessoais, autonomia e foca nas 
necessidades e direitos do indivíduo. O segundo modelo, interdependente, privilegia metas grupais e a focalização de papéis sociais, deveres e obrigações. E o modelo autônomo-relacional, compreende características combinadas dos modelos anteriores, em que o selfé definido como autônomo quanto a sua ação e relacional no que tange à proximidade interpessoal. Esses modelos, por sua vez, variam segundo o contexto em que a pessoa vive e que seus descendentes viveram, sua classe social, nível de escolaridade, ocupação, idade, etc.

Martin e Johnson (1992 apud Lordelo et al., 2000) discutem sobre a relação entre as crenças dos pais sobre o desenvolvimento e a percepção materna e paterna da competência infantil e concluem que pais com um conhecimento mais sofisticado sobre teorias do desenvolvimento infantil e da aprendizagem tenderiam a perceber as crianças como mais competentes. Isso porque entende-se que os pais com teorias mais sofisticadas tendem a se tornarem mais observadoras de suas crianças, embora uma direção inversa de causalidade seja também plausível.

A teoria cognitivo-comportamental - TCC supõe que há sempre um processamento cognitivo e avaliação de eventos internos e externos - mediação cognitiva - que pode influenciar a resposta emocional e comportamental a esses eventos (Knapp \& Beck, 2008). Assim sendo, expõe-se sobre as necessidades emocionais fundamentais que são abordadas pela terapia do esquema, uma TCC mais abrangente do que a TCC tradicional, criada por Young, Klosko e Weishaar (2008) e que se fundamenta na teoria do apego elaborada por Bowlby, a qual postula que a qualidade do vínculo oferecido pela mãe ou cuidador ao bebê terá repercussões ao longo de toda a sua vida, gerando modelos de funcionamento interno.

De acordo com os pressupostos da terapia do esquema, a criança precisa, para ter suas necessidades emocionais atendidas, estabelecer vínculos seguros com outros indivíduos, o que inclui segurança, estabilidade, cuidado e aceitação; deve ter também sua autonomia, competência e sentido de identidade respeitados; além de liberdade de expressão e necessidades e emoções válidas; momentos de espontaneidade e lazer são imprescindíveis e; limites realistas e de autocontrole devem estar presentes. A satisfação dessas necessidades fundamentais são requisitos para o desenvolvimento de um indivíduo 
psicologicamente saudável e capaz de se adaptar ao ambiente (Young et al., 2008).

Caso os fatores supracitados não sejam suficientemente atendidos, o sujeito pode desenvolver esquemas desadaptativos remotos que, por sua vez, são capazes de vir a atrapalhar seu fluxo saudável de vida. Tais esquemas resultam em incapacidade de formar vínculos seguros e satisfatórios, não desenvolverem relação de reciprocidade ou autodisciplina apropriadamente, podem suprimir seus sentimentos e impulsos espontâneos, além de não terem senso de individualidade e autonomia (Young et al., 2008).

Alinhada a essas informações e fazendo uma referência específica a cultura alemã, cita-se que é típico de seus descendentes uma postura um tanto quanto rígida, levando essas pessoas a se comportarem segundo alguns padrões preestabelecidos, dificultando a manifestação de seus próprios desejos, ou agindo segundo seus sentimentos. Sujeitos que foram criados em famílias de origem alemã relataram ter crescido com falta de demonstrações afetivas por parte de seus pais, além de perceberem a existência de certas dificuldades na conversação com os mesmos (Groth \& Hoch, 2011). Macarini et al. (2010) complementa afirmando que o modelo de self predominante na tradição, segundo a literatura, é independente e autônomo.

Hillebrand (2006) aponta também para a resistência na expressão de afetos e sentimentos desse povo, que talvez tenha "sido a forma encontrada pela sociedade, em algum momento de sua existência, para controlar os instintos" (Hillebrand, 2006, p. 66), tal padrão teria sido transmitido no decorrer das gerações desde o período colonial e se tornou determinante na forma de relacionamento entre as pessoas, por meio da religião, escola e família.

Esses esclarecimentos são importantes no que concerne o objetivo desse artigo, que é conhecer aspectos diversos da criação dos filhos quando os pais possuem origem alemã, relacionando tais aspectos em um diálogo interdisciplinar entre as teorias cognitivas e culturais. Na realização do estudo que antecedeu essa produção, foi dado especial enfoque às necessidades emocionais fundamentais que os filhos demandam de seus pais e como estes percebem e reconhecem essas necessidades em seus filhos, tendo em vista aspectos e modelos culturais 
de parentalidade. Esse trabalho se justifica pelo fato de que as TCCs cada vez mais valorizam a sensibilidade cultural. Portanto, produções que estimulem o diálogo entre Psicologia Clínica e aspectos culturais visam o melhoramento da conceitualização cognitiva dos pacientes, focando não apenas nos aspectos cognitivos e comportamentais, mas também em aspectos sócio-culturais, incluindo questões como preconceito e racismo.

\section{Método}

O presente trabalho utilizou-se de uma abordagem qualitativa, em que não há preocupação com representatividade numérica, mas sim com o aprofundamento do entendimento de determinado grupo social ou de uma organização (Gerhardt \& Silveira, 2009). Quanto aos objetivos, trata-se de um estudo descritivo. A pesquisa descritiva "observa, registra, analisa e relaciona fatos ou fenômeno sem manipulação" (Gonçalves et al., 2014, p. 33). Em relação ao desenho, configura-se como um trabalho transversal, utilizado quando duas ou mais amostras de populações são delimitadas para estudo em um período de tempo específico (Shaughnessy, Zechmeister \& Zechmeister, 2012).

Para a coleta de dados, foram realizadas entrevistas semiestruturadas e não diretivas, com seis pais de descendência alemã, residentes da Mesorregião Norte Catarinense. Por entrevista semiestruturada, entende-se aquela que possui um roteiro previamente elaborado, apoiado em teorias e hipóteses que interessam à pesquisa (Triviños, 1987). A amostra aqui se definiu como não probabilística, em que os respondentes são selecionados com base na sua disponibilidade e disposição para responder (Shaughnessy et al., 2012).

A colonização da região em que a pesquisa aconteceu está altamente vinculada à Alemanha, especialmente ao norte deste país (Richter, 1989). O patrimônio histórico cultural preserva a memória de características arquitetônicas, gastronomia, idioma, músicas, danças e festas típicas herdadas dos antepassados que migraram para as terras catarinenses.

O roteiro de entrevista semiestrurada foi composto por questões que versam sobre os seguintes temas: o que as crianças/adolescentes precisam dos pais; dificuldades para oferecer coisas consideradas 
importantes; práticas e modelos educativos; fatores que levam ao mal comportamento; como lidam com as emoções expressas pelos filhos; incentivo a autonomia e independência, considerando a faixa etária; pensamentos sobre limites; e relevância de se ter momentos de lazer e espontaneidade. As entrevistas ocorreram a partir de gravação de voz e o material coletado foi, posteriormente, transcrito na íntegra.

\section{Participantes}

Para este estudo foram entrevistadas seis pessoas, mediante o seguinte critério de inclusão: ter filhos e ser de descendência alemã. Os participantes foram assim identificados: 1A, 2A, 3A, 4A, 5A e 6A.

Apenas o entrevistado 6A era do sexo masculino, e todos tinham idade superior a 50 anos, sendo $2 \mathrm{~A}$ a mais idosa (82 anos). 1A e 2A nasceram na Alemanha e vieram para o Brasil na infância, e os familiares de $3 \mathrm{~A}, 4 \mathrm{~A}, 5 \mathrm{~A}$ e $6 \mathrm{~A}$ chegaram às terras brasileiras há duas gerações, os quais estiveram sempre estabelecidos em Santa Catarina.

Uma entrevistada possui ensino superior completo em Enfermagem; duas possuem magistério, tendo atuado como professoras e já sendo aposentadas; o restante não concluiu o ensino fundamental. Todos os participantes reconhecem ter sido criados em famílias que seguiam tradições alemãs e que reproduziram características dos ancestrais em seus estilos de parentalidade. Apesar da região em que a pesquisa ocorreu ter sido majoritariamente colonizada por ancestrais da Alemanha e preservar aspectos desse povo, os pesquisadores reconhecem que os participantes tiveram suas concepções e formas de parentalidade pelo menos parcialmente influenciadas por culturas e sociedades distintas na constituição familiar.

Faz-se importante ressaltar que os participantes tiveram seu anonimato preservado, mediante a assinatura do Termo de Consentimento Livre e Esclarecido - TCLE. O estudo não passou pelo Comitê de Ética em Pesquisa por se tratar de atividade de ensino da graduação.

\section{Análise dos dados}

O método para análise dos resultados obtidos foi a Análise de Conteúdo apresentada por Franco (2012, p. 12), cujo ponto de partida "é a mensagem, seja ela verbal (oral ou escrita), gestual, silenciosa, figura- 
tiva, documental ou diretamente provocada". Nesse sentido, na Análise de Conteúdo deve ser principalmente interpretado o sentido que um indivíduo atribui às mensagens (Franco, 2012).

A primeira fase da Análise de Conteúdo consistiu na pré-análise. Na segundo fase foram efetuados recortes do texto em unidades comuns denominadas de categorias, as quais foram tabeladas. Por último, houve o tratamento dos dados, com a finalidade de interpretar os resultados à luz de teorias cognitivas e culturais (Franco, 2012).

Ao todo, participaram da pesquisa cinco pesquisadores: dois contribuíram principalmente como entrevistadores e auxiliaram nas transcrições; dois realizaram as transcrições, categorização e análise dos dados e redação; e um foi responsável pelo delineamento metodológico, contribuições teóricas e revisão do manuscrito. A coleta de dados e transcrição das entrevistas ocorreu nos meses de agosto e setembro de 2018.

\section{Resultados e discussões}

As questões que nortearam as entrevistas diziam respeito principalmente às necessidades emocionais fundamentais que os pais verificaram existir e tentavam suprir na criação de seus filhos. Segundo a teoria da emoção de Richard Lazarus (Gonçalves, 2014), as emoções têm impacto direto sobre o que o indivíduo faz e a maneira como o faz. Esta, no que lhe concerne, interliga-se a aspectos como a cognição, motivação, atividade fisiológica e a movimentos adaptativos e padronizados.

A partir dos dados coletados emergiram seis categorias de análise. Tais categorias correspondem à: a) vínculos seguros como principal necessidade emocional; b) dificuldades dos pais: fatores socioeconômicos e pouca liberdade de expressão; c) concepções sobre os modelos de criação; d) mau comportamento: a falta de limites realistas e as influências externas; e) o incentivo à autonomia supervisionada; e f) dimensão da autonomia em contraste à espontaneidade.

A discussão dos resultados embasou-se nos cinco domínios de necessidades emocionais propostos por Young et al. (2008). São eles: o primeiro domínio corresponde ao vínculo seguro com outros indivíduos; o segundo à autonomia, competência e sentido de identida- 
de; o terceiro diz respeito à liberdade de expressão e necessidades e emoções validadas; o quarto domínio se dirige à necessidade de espontaneidade e lazer; e, por fim, o quinto e último domínio condiz aos limites e de autocontrole (Young et al., 2008).

\section{Vínculos seguros como principal necessidade emocional}

Amor, carinho, presença dos pais, segurança, apoio, parceria, atenção, cuidado e acolhimento foram palavras que os entrevistados utilizaram para descrever a necessidade emocional de vínculo seguro com outros indivíduos, sendo que as três primeiras apareceram com mais frequência em suas falas.

Segundo Young et al. (2008), pessoas com vínculos seguros recebem proteção, segurança, estabilidade, cuidado e empatia. Relacionando as respostas dos participantes, têm-se que apoio e parceria vinculam-se à segurança. Amor, carinho, atenção e acolhimento fazem parte do cuidado e empatia. Presença dos pais relaciona-se à proteção. Juntas, essas características conferem um senso de estabilidade ao indivíduo em desenvolvimento.

Ressalta-se que os participantes foram unânimes ao responder o que os filhos mais precisam dos pais com as necessidades do primeiro domínio.

\section{Dificuldades dos pais: fatores socioeconômicos e pouca liberdade de expressão}

A respeito das maiores dificuldades para oferecer aquilo que os participantes pensam ser importante para os filhos, surgiram dois diferentes eixos de análise. No primeiro eixo, dois terços dos participantes percebem dificuldades relacionadas aos fatores socioeconômicos. A participante 1A problematiza a valorização de bens materiais para suprir a presença física dos pais. Nessa perspectiva, $6 \mathrm{~A}$ reconhece que às vezes não consegue dar a atenção que gostaria aos filhos, pois a dificuldade é ter dinheiro e dispor de tempo. Esses participantes relacionam explicitamente as necessidades emocionais dos filhos às dificuldades percebidas.

Já 2A queixa-se que atualmente "essa maneira de viver e educar os filhos está tudo muito caro, muito inacessivel para a maioria das pes- 
soas", encontrando mais dificuldades para encaminhá-los para a escola e o mercado de trabalho. Nota-se, em sua fala, uma mudança de ordem econômica que impacta diretamente no estilo de vida das pessoas e, por consequência, na criação dos filhos.

A participante 4A discorre sobre o viés econômico, porém, enfatiza a importância dada ao trabalho como forma de ascender socialmente e custear os estudos. Em suas palavras: aos "[...]16 anos eu falei pro meu pai: 'pai eu quero trabalhar.' Ele disse: 'você precisa estudar'". Posteriormente, evidencia que as influências recebidas de seus pais repercutem na criação de suas filhas, conforme a seguinte fala:"a gente sempre primou pela qualidade e a gente sempre pagou colégio particular, violão, computação, né? [...] todas as coisas que a gente pode dar pra ajudar elas a fazer um bom processo cultural e educacional [...]".

Nesse sentido, Lahire (2004) concebe a estrutura do comportamento e da personalidade da criança como incompreensíveis fora das relações sociais. Suas ações são reações que se sustentam, de forma relacional, nas ações dos adultos. O universo doméstico, através da ordem material, afetiva e moral, pode desempenhar um papel importante no alcance ou conquista de um capital econômico, social e cultural que conduzem ao "fracasso" ou "sucesso" escolar. A criança que se desenvolve em um ambiente doméstico material e temporalmente ordenado adquire métodos de organização, estruturas cognitivas ordenadas e propensas a atuar como estruturas de ordenação do mundo.

No segundo eixo, encontra-se uma dificuldade pertencendo à satisfação de necessidades emocionais do terceiro domínio relacionado à liberdade de expressão (Young et al., 2008). A participante 5A aponta dificuldade para tratar de temas que são tabus sociais, sobretudo no que tange à sexualidade. Por fim, 3A cita os hábitos alimentares vinculados a um desenvolvimento saudável como uma dificuldade das crianças e adolescentes aceitarem aquilo que é imposto pelos pais, isto é, uma dificuldade de estabelecer limites e autocontrole (quinto domínio), os quais auxiliam na construção de disciplina, responsabilidade, cumprimento de objetivos pessoais e cooperação ao longo do desenvolvimento do indivíduo (Young et al., 2008).

Setton (2002) discorre sobre a teoria do habitus em Pierre Bourdieu. Para a autora, 
Habitus é então concebido como um sistema de esquemas individuais, socialmente constituído de disposições estruturadas (no social) e estruturantes (nas mentes), adquirido nas e pelas experiências práticas (em condições sociais específicas de existência), constantemente orientado para funções e ações do agir cotidiano. Pensar a relação entre indivíduo e sociedade com base na categoria habitus implica afirmar que o individual, o pessoal e o subjetivo são simultaneamente sociais e coletivamente orquestrados (Setton, 2002, p. 63).

Sendo assim, tem-se que as disposições estruturantes da teoria do habitus constituem a cognição. O que diferencia essa teoria da terapia do esquema é que os esquemas da segunda não dizem respeito apenas ao agir cotidiano; a não satisfação de necessidades emocionais gera esquemas remotos desadaptativos constituídos por crenças arraigadas que distorcem a percepção que o indivíduo possui sobre ele mesmo e o mundo, podendo influenciar suas ações e seu agir cotidiano.

As cinco necessidades emocionais não satisfeitas geram esquemas que pertencem aos seguintes domínios: I) desconexão e rejeição; II) autonomia e desempenho prejudicados; III) limites prejudicados; IV) direcionamento para o outro; V) supervigilância e inibição (Young et al., 2008). A contribuição de Bourdieu consiste nas disposições estruturadas, isto é, fundamenta a influência do social sobre a cognição. Dessa forma, quando 5A aponta a dificuldade de falar sobre sexualidade deve-se, para uma análise mais abrangente, considerar o contexto social no qual ela está inserida.

\section{Concepções sobre os modelos de criação}

No tocante a presença de um modelo de criação, para 3A é essencial aprender com as falhas e repetir o que dá certo, guiando-se por valores morais e éticos. Ela cita mudanças históricas na sociedade na forma de criar os filhos. Percebe que na atualidade "os pais estão muito preocupados, lendo tudo, às vezes sem saber o que fazer". O discurso da participante 4A exemplifica essa colocação. Ela cita que seu maior medo durante a gestação era de não saber educar. Para tanto, leu obras do psiquiatra Içami Tiba. No livro "Disciplina, limite na medida certa", o autor responde às principais dúvidas dos pais numa linguagem acessível ao público leigo acerca das seguintes temáticas: responsabilidade, liberdade, limites e disciplina (Tiba, 1996). 
A participante 4A ainda traz que seu conhecimento teórico, além das suas experiências e vivências, lhe deram uma base mais sensível e intuitiva para lidar com as necessidades emocionais de suas duas filhas, uma vez que sua relação com a mãe não parecia suprir a necessidade emocional de vínculo seguro e ter pouco caráter afetivo. Sobre isso, ela relata:

Hoje eu, olhando pra trás, eu vejo a minha mãe, a minha mãe ela não te dá carinho, ela te dá um abraço, mas se você quiser dar um beijo nela assim, dar um afago mais acentuado assim, ela: 'tá bom, tá bom, tá bom, ela faz assim sabe, então eu tinha muito disso e eu fui percebendo com o tempo, à medida que as meninas foram crescendo, eu fui perdendo isso.

Assim, essa entrevistada e também 1A, 5A e 6A, percebem influências da criação que recebeu de seus próprios pais. A diferença é que $1 \mathrm{~A}$ aponta para uma criação "tradicional alemã" e "religiosa", enfocando a necessidade de se estabelecer limites: "as crianças precisam às vezes se confrontar com um 'não', né, para elas sentirem que as coisas não é bem como eles querem". A mesma ainda salienta que, por vezes, devese deixar que os filhos tomem suas próprias decisões e façam suas escolhas e que eles também arquem com as consequências delas.

Por outro lado, 4A, 5A e 6A fazem apontamentos sobre aspectos que consideram "ruins" e devem ser repensados ou, ainda, que foram bons e devem ser reproduzidos, em relação à educação que elas mesmas receberam. A participante 5A refere que seu modelo de criação foi também aprendido no colégio: “Tentar, né, ser mais aberto, mais carinhoso, diferente de como a gente foi criado". Para 6A, em contrapartida: "Foi bem mais ou menos a mesma coisa que meus pais, só que mais rígido, mais firme em algumas coisas, botando mais limites e sendo mais rigoroso [...]". No que se refere à necessidade de limites realistas, 1A também relata que os seus pais eram mais modernos e que deixavam sair na época da adolescência, atribuindo-lhe responsabilidades numa relação de confiança: "você tem que ter confiança, eu vou depositar um $x$ confiança em você, espero que você corresponda a essa confiança que estou dando".

A participante 3A, nessa mesma perspectiva, ao afirmar que nunca estudou e que todo seu conhecimento deriva da prática, verbaliza: 
"está dentro de sua personalidade aquilo que seus pais te ensinaram ou quando você sente meio perdido você procura um conselho de um amigo". Nessas passagens fica evidenciada a repercussão que a cultura tem na criação das mais diversas gerações e a relação do conhecimento com a competência parental.

\section{Mau comportamento: a falta de limites realistas e as influências externas}

Quando a questão do mau comportamento foi abordada, estipulou-se um consenso entre os entrevistados de que a falta de limites dados pelos pais e as influências externas são os maiores causadores. A entrevistada $2 \mathrm{~A}$ pontua que o excesso de liberdade, as más influências e outras situações do cotidiano são os principais motivos de comportamentos inapropriados. Tais ocasiões, segundo $3 \mathrm{~A}$, se dariam principalmente durante a adolescência, pois:

Quando você tem um filho adolescente ele começa a escapar debaixo da asa, ele sai, ele vai tendo convivência, a partir da escola, depois da escola outros cursos e aquele círculo não é tão sadio e ai vem as más influências e as coisas acontecem e você vê seu filho fazendo as coisas que menos esperam.

Nesse mesmo ponto de vista, $5 \mathrm{~A}$ levanta para a ausência dos pais no cotidiano dos filhos, principalmente nas últimas décadas, o que levaria, de acordo agora com o participante $6 \mathrm{~A}$, a falta de suporte, de limites, rigidez. Ele ressalta a importância dos pais agirem como exemplo para seus filhos, uma vez que as crianças se portam de acordo com a mesma regra de conduta utilizada por aqueles que são seus modelos. Hillebrand (2006), assim, traz que pais com problemas de relacionamentos interpessoais, por exemplo, podem comprometer a qualidade do relacionamento e até mesmo oferecer modelos inadequados de desempenho social para os filhos.

Bandura (2008) ao discutir o conceito de modelação social, traz que as pessoas padronizam seus estilos de pensamento e comportamento conforme arquétipos funcionais de outras pessoas, os quais funcionam como guias para a produção de desempenhos hábeis. Essas habilidades, que são aperfeiçoadas com repetidos ajustes corretivos na igualação de concepções, necessitam de um feedback instrutivo, que acompanha as ações e proporciona informações necessárias para de- 
tectar e corrigir diferenças entre concepções e ações, de maneira que as competências desejadas sejam dominadas. Nesse sentido que a concepção de $6 \mathrm{~A}$ se mostra importante, uma vez que ele também cita a incoerência existente entre o comportamento de um pai, que é reproduzido pelo filho que, por sua vez, recebe represália e um feedback negativo por agir da mesma maneira que, anteriormente, o pai agiu. A incompatibilidade existente aqui poderia ser reduzida caso o pai tivesse conhecimento de processos de modelação, conforme traz Bandura (2008) e em concordância com o que já foi discutido na fundamentação teórica deste artigo.

O mau comportamento também poderia ser resultado da afronta, de uma necessidade de testar até onde seus limites podem ir. Essa lógica levantada por 4A funcionaria como um jogo de limites, que exigem que os pais enfrentam as crianças e adolescentes, que aprendam com eles e também saibam quando ceder ou acordar e quando se manter firme perante uma decisão.

\section{O incentivo à autonomia supervisionada}

Quando questionados sobre a maneira de lidar com as emoções dos filhos, os entrevistados mostraram respostas semelhantes entre eles. Pontua-se o diálogo, o conforto e o acolhimento como principais estratégias, além do exercício do conselho. A participante $4 \mathrm{~A}$ relata aqui o momento em que sua filha começou a namorar um menino mais velho que estabeleceu com ela uma relação abusiva. Apesar de $4 \mathrm{~A}$ e seu esposo, também de origem alemã, atentarem a filha para a situação não ideal de relacionamento, eles não impuseram qualquer tipo de proibição, dando-lhe autonomia para decidir.

Teixeira, Oliveira e Wottrich (2006) coletaram informações que vão ao encontro das práticas parentais de incentivo a autonomia (segundo domínio) a partir de Escalas de Práticas Parentais - EPP que foram aplicadas a adolescente de origens e etnias abrangentes. Os autores trazem o incentivo a agir de maneira independente, o aprender com os próprios erros, o estímulo a decisões e opiniões como componentes das práticas autônomas, as quais apresentam um índice igual a 0,76 , em uma escala que vai até 01 . Toda a liberdade dada, entretanto, é acompanhada pela supervisão do comportamento, que concerne a atitudes dos pais de supervisão do comportamento dos filhos buscando con- 
hecer suas atividades ao invés de lhes impor restrições explícitas. Essa não proibição com exigências e busca pela autonomia se mostra marcante na cultura alemã e se alinha ao apresentado nas entrevistas, que coloca a responsabilidade do indivíduo de forma muito acentuada, com enfoque na escolha e responsabilização.

\section{Dimensão da autonomia em contraste à espontaneidade}

Quanto a necessidade de quarto domínio (Young et al., 2008), a entrevistada 1 A traz a importância de se "ter amigos, sair, jogar bola, andar de bicicleta, porque isso faz com que a criança se conscientize do que é o mundo né, e vai percebendo as... as multifacetas que o mundo nos oferece." A brincadeira, o processo lúdico e criativo, a imaginação, a não supressão de sentimentos e/ou emoções e o lazer se mostram importantes e presentes na fala de todos os entrevistados que, entretanto, não deram tanta ênfase ao brincar junto das crianças. $\mathrm{O}$ entrevistado $6 \mathrm{~A}$, por exemplo, trouxe que "É bom né, eles brincarem, gastarem as energias e se divertirem, sempre com regras, claro. Fazer amigos né," não se colocando como alguém presente e ativo nos momentos de brincadeira.

Complementando essa colocação, 1A relata que a ausência dos pais nas brincadeiras se daria pelo "fato deles quererem trabalhar e darem mais valor a sua vida profissional", o que resultaria, por sua vez, no excesso de atividades e no pouco tempo de interação entre pais e filhos, conforme também evidenciado nas dificuldades inicialmente percebidas. Ela cita que as crianças são colocadas em "colégio de manhã, aula de balé, aí aula de piano, aula de inglês, aula disso e aula daquilo... e a criança não tem tempo de ser criança." Faz-se uma ressalva aqui de que existe uma percepção de que os momentos de espontaneidade fazemse ausentes, segundo 1A, principalmente no século atual.

Dentro dessa mesma necessidade emocional, discute-se sobre a posição dos pais frente à livre expressão das emoções dos filhos e como eles agem perante as inclinações próprias dos mesmos; nesse quesito, os entrevistados se mostraram eminentemente cautelosos e rigorosos. Eles falam em estabelecer deveres, valores e responsabilidades para as crianças desde a tenra idade. Sobre isso, 1A expõe: "tem que aprender a guardar os brinquedos que sujou, entendeu - já tem que criar uma certa responsabilidade, mesmo uma criança de 2 anos." A participante 3A 
também traz que propunha a sua filha ir à escola sozinha, mesmo que outros pais mostrassem estranhamento à atitude adotada.

A entrevistada 2A comunica outra preocupação:

Acho que os filhos hoje em dia são criados com muita liberdade e liberdade demais não é bom, pois envolve em más influências e um certo valor que até lá podemos dizer, mais adiante não. Liberdade para os filhos tudo bem, mas não demais, eles precisam saber que tudo que eles fizerem na vida têm consequências.

Examina-se o enfoque constante dado pelos entrevistados à liberdade de ir e vir e aos limites, também a importância da autonomia, independência e da disciplina como base para qualquer relação. As necessidades emocionais fundamentais de autonomia e competência (segundo domínio) e de limites realistas e autocontrole (quinto domínio), discutidas anteriormente por Young et al. (2008) podem ser alinhadas, assim, ao modelo de self independente de Macarini et al. (2010). Apesar da valorização de habilidades relacionais nos filhos, os entrevistados trouxeram falas que valorizavam mais a dimensão autônoma. O desenvolvimento da independência e autonomia, assim como do auto-aperfeiçoamento e autocontrole da criança, por sua vez, depende do aumento da autoestima e autoconfiança dos filhos (Macarini et al., 2010).

A participante 1A traz uma reflexão sobre a autoestima da criança e a relação que ela estabelece com os pais. Ela traz a importância do afeto, da valorização, do carinho, do diálogo e da educação na criação dos filhos. Frisa que eles devem ter metas a cumprir e que, ao serem cumpridas, devem receber elogios genuínos. Engaja-se a prática trazida à necessidade de aprovação e validação emocional (terceiro domínio) que se faz imprescindível ao desenvolvimento e manutenção de crenças e pensamentos adaptativos (Young et al., 2008).

\section{Considerações finais}

As crenças parentais emergem como um campo de estudos relevante para a compreensão do desenvolvimento humano em seu aspecto intelectual, afetivo-emocional e social. A TCC fundamenta os desdobramentos que essas crenças podem ter na vida adulta dos filhos. 
Pontua-se que a única característica em comum a todos os participantes é terem origem alemã e possuírem filhos. As maiores limitações deste estudo foram o número pequeno da amostra e o nível de formação heterogêneo dos participantes. Ainda assim, foi possível perceber semelhanças em seus discursos a respeito da criação dos filhos. Destaca-se que os participantes foram unânimes ao conceber a necessidade emocional de primeiro domínio como hierarquicamente superior às demais. Além desta, as necessidades de segundo e quinto domínio foram também enfatizadas.

Para a maioria dos entrevistados, as principais dificuldades para criar os filhos versam sobre o viés econômico e a disponibilidade de tempo - apesar de valorizarem momentos de espontaneidade e lazer e de estarem presentes. Percebe-se que eles almejam que seus filhos sejam socialmente bem-sucedidos, investindo, dessa forma, na educação formal. No entanto, chegam a admitir que outros aspectos da educação, por vezes, são negligenciados. Compreende-se que essa dificuldade que os pais possuem não é característica diferencial da cultura alemã, mas são próprias das sociedades ocidentais.

Fica evidente no discurso dos entrevistados que as influências recebidas de seus próprios pais repercutem na criação de seus filhos. Os participantes referem manter as características que consideram positivas na educação que receberam e tentam modificar suas atitudes naquilo que consideram como experiências negativas. Nota-se que os pais com maior nível de escolaridade possuem teorias mais sofisticadas sobre a criação dos filhos e, assim, maior segurança para educá-los e relacionar-se com eles.

Acrescenta-se que uma das limitações do estudo ora proposto se dá no baixo número de participantes e na ausência de uma amostra comparativa para relacionar características específicas encontradas na paternidade dos pais de descendência alemã. Além disso, frisase que os pais, quando inseridos em outra cultura, mesmo que a Mesorregião Norte Catarinense seja majoritariamente povoada por descendentes alemães que preservam diversas tradições desses colonizadores, são influenciados por uma diversidade de ambientes sociais e culturais, o que reflete nas suas concepções, características e formas de parentalidade. 
Portanto, com o presente estudo foi possível conhecer aspectos diversos da criação dos filhos quando os pais possuem origem alemã em um diálogo interdisciplinar entre a TCC e teorias culturais. Assim, pontua-se que trabalhos posteriores podem ser desenvolvidos no intuito de averiguar as necessidades emocionais do terceiro e quarto domínio: liberdade de expressão e emoções validadas e espontaneidade e lazer, visto que elas constituem o aspecto afetivo-emocional e social do desenvolvimento humano e não foram abordados de maneira tão ampla aqui.

\section{Referências}

Bandura, A.; Azzi, R. G. \& Polydoro, S. (2008). Teoria Social Cognitiva: conceitos básicos. Porto Alegre: Artmed.

Brás, P. M. F. (2008). Um olhar sobre a parentalidade (estilos parentais e aliança parental) à luz das transformações sociais actuais (Dissertação de mestrado). Universidade de Lisboa, Lisboa, Portugal.

Cia, F., Pereira, C. S., Del Prette, Z. A. P., \& Del Prette, A. (2006). Habilidades sociais parentais e o relacionamento entre pais e filho. Psicologia em Estudo, 11, 73-81. Recuperado de http://www. redalyc.org/articulo.oa?id=287122090009

Franco, M. L. P. B. (2012). Análise de conteúdo (4ª ed.). Brasília: Liber Livro.

Gerhardt, T. E.; Silveira, D. T. (2009). Métodos de pesquisa. Porto Alegre: Editora UFRGS.

Gonçalves, C. H. (2014). A terapia cognitiva e a teoria cognitiva da emoção de Lazarus (Dissertação de mestrado). Universidade Federal de Juiz de Fora, Juiz de Fora, Brasil. Recuperado de https://repositorio.ufff.br/jspui/bitstream/ufjf/841/1/ carloshenriquegoncalves.pdf

Gonçalves, M. L. et al. (2014). Fazendo pesquisa: do projeto à comunicação científica ( $4^{\mathrm{a}}$ ed.). Joinville: Editora Univille.

Groth, C., \& Hoch, V. (2011). A expressão emocional nos descendentes germânicos. Unoesc \& Ciência - ACHS, 2(1), 29-38. Recuperado de https://editora.unoesc.edu.br/index.php/achs/article/view/553

Hillebrand, M. (2006) Cantos tradicionais: uma leitura da cultura germânica (Dissertação de mestrado). Universidade de Caxias do Sul - UCS, Caxias do Sul, Brasil. Recuperado de https:// repositorio.ucs.br/handle/11338/118 
Knapp, P., \& Beck, A. T. (2008). Fundamentos, modelos conceituais, aplicações e pesquisa da terapia cognitiva. Revista Brasileira de Psiquiatria, 30, 54-64. Recuperado de https://dx.doi. org/10.1590/S1516-44462008000600002

Lahire, B. (2004). Sucesso escolar nos meios populares: razões do improvável. São Paulo: ABDR.

Lordelo, E. R,, Fonseca, A. L., \& Araújo, M. L. V. B. (2000). Responsividade do ambiente de desenvolvimento: crenças e práticas como sistema cultural de criação de filhos. Psicologia: Reflexão e Crítica, 13(1), 73-80. Recuperado de https://dx.doi. org/10.1590/S0102-79722000000100009

Macarini, S. M., Martins, G. D. F., Sachetti, V. A. R., \& Vieira, M. L. (2010). Etnoteorias parentais: um estudo com mães residentes no interior e na capital de Santa Catarina. Psicologia: Reflexão e Crítica, 23(1), 37-45. Recuperado de https://dx.doi. org/10.1590/S0102-79722010000100006

Richter, K. (1989). Recuperação de fontes sobre a colonização alemã no norte de SC. ÁGORA: Arquivologia em debate, 5(9), 1222. Recuperado de https://www.brapci.inf.br/_repositorio/2015/12/pdf_353cffddda_0000015098.pdf

Setton, M. G. J. (2002). A teoria do habitus em Pierre Bourdieu: uma leitura contemporânea. Revista Brasileira de Educação, 60-70. Recuperado de https://dx.doi.org/10.1590/S141324782002000200005

Shaughnessy, J. J., Zechmeister, E. B., \& Zechmeister, J. S. (2012). Metodologia de pesquisa em psicologia (9a ed.). Porto Alegre: AMGH Editora.

Teixeira, M. A. P., Oliveira, A. M., \& Wottrich, S. H. (2006). Escalas de Práticas Parentais (EPP): Avaliando Dimensões de Práticas Parentais em Relação a Adolescentes. Psicologia: Reflexão e Crítica, 19(3), 433-441. Recuperado de http://www.scielo. $\mathrm{br} / \mathrm{pdf} / \mathrm{prc} / \mathrm{v} 19 \mathrm{n} 3 / \mathrm{a} 12 \mathrm{v} 19 \mathrm{n} 3 . \mathrm{pdf}$

Tiba, I. (1996). Disciplina, limite na medida certa. São Paulo: Editora Gente.

Triviños, A. N. S. (1987). Introdução à pesquisa em ciências sociais: a pesquisa qualitativa em educação. São Paulo: Atlas.

Young, J. E., Klosko, J. S., \& Weishaar, M. E. (2008). Terapia do Esquema: guia de Técnicas Cognitivo-Comportamentais Inovadoras. Porto Alegre: Artmed. 